\title{
Information structure and phrase length as predictors of AP-initial accents
}

\author{
James German \\ Laboratoire Parole et Langage (LPL) \\ james.german@lpl-aix.fr \\ Mariapaola D'Imperio \\ Laboratoire Parole et Langage (LPL) \\ mariapaola.dimperio@lpl-aix.fr
}

\section{Introduction}

In French, utterances are parsed into a series of phrasal units, which minimally consist of a prosodic word (typically a content word plus zero or more associated functional items) and define the domain of stress and tone assignment. It is generally agreed that these units are obligatorily marked by a prominent F0 rise on the last full syllable of the phrase (excluding word-final schwa), and optionally include an additional rise near the beginning of the phrase, typically on the first or second syllable of the first content word occurring in the phrase. In addition, the final rise corresponds to a general increased level of acoustic prominence and lengthening for the syllable on which it occurs, while the early rise is less clearly linked with lengthening.

In this paper, we analyze the structure of these phrasal units within the autosegmental framework of Jun \& Fougeron $(2000,2002)$. In that framework, words are parsed into accentual phrases (APs), whose structure can be characterized by a sequence of high and low tones associated to specific syllables within the phrase. Each AP obligatorily includes a final accent $\left(\mathrm{H}^{*}\right)$, which associates to the last full syllable (i.e., non-schwa) of the AP, and optionally includes an initial accent (Hi), which typically associates to the first or second syllable of the first content word in the AP. Each of these high tones is preceded by a single low tone, which may be optionally deleted in certain cases. Thus, a maximal AP consists of the sequence LHiLH*, while a minimal AP would consist of just the sequence $\mathrm{LH}^{*}$. Other well-formed and attested sequences include $\mathrm{LLH}^{*}, \mathrm{LHiH}^{*}$ and $\mathrm{HiLH}^{*}$.

It is generally accepted that utterances may be partitioned at a level of pragmatic interpretation in a way that reflects how the meaningful parts of the utterance relate to the context. In general, this includes a two-way distinction between a background, including information that is shared by interlocutors or in some sense "old", and a focus, comprising information that is presented by the speaker as somehow novel. In many languages, this partition is marked through prosodic form, though the extent to which this is the case for French remains an open question. Previous work addressing this question emphasizes a notion of focus reflecting contrasting elements in corrective or emphatic contexts. In other words, focus is defined operationally as that element in an utterance that corrects or overrides a particular aspect of a preceding utterance. In example (1) from Jun \& Fougeron (2000), for example, the focus is assumed to be the noun phrase des bananes ('bananas') since that element contrasts with the negated element des ananas ('pineapples') in the preceding utterance.

(1) i. Marion ne mangera pas des ananas au petit déjeuner, mais...

'Marion will not eat pineapple for breakfast, but...'

ii. Marion mangera [des bananes]F au petit déjeuner.

'Marion will eat bananas for breakfast.' 
Typically, such a contrastively focused element is said to be marked by a single rising-falling contour, which is distinct in various respects from either the early or late rise, and which may be realized on either final or non-final syllables in the phrase. For Di Cristo (1996), for example, this is the accent d'insistance. For Jun \& Fougeron $(2000,2002)$, it is the focus accent, or $H f$, which they show experimentally to consist of a rise that is both higher and aligned later than a typical AP-final accent in a broad focus context. The region following the contrastive element, or the post-focal region, is often characterized by the absence of prominent pitch movements (Touati, 1987; Di Cristo 1996; Clech-Darbon et al., 1998; Jun \& Fougeron, 2000), a phenomenon variously referred to as deaccenting or dephrasing. The region preceding the focused element, by comparison, typically retains the early and late rises associated with regular phrasing, and in this sense is not markedly different from the same region under a broad focus pattern. However, there is some evidence that the tonal movements in this region have a compressed pitch range (Touati, 1987; Jun \& Fougeron, 2000; Dohen \& Loevenbruck, 2004) and a reduced number of phrase boundaries (Dohen \& Loevenbruck, 2004). Féry (2001) explores the marking of focus in contexts involving direct answers to $w h$-interrogatives. While no quantitative findings are presented, the study suggests an overall tendency or preference for a focus to be phrased as a single unit. The pre-focal region also shows this tendency, though a syntactic subject is generally phrased separately regardless of its relationship to the focus.

It is generally agreed that the transition from the focal region to the post-focal region is readily identified in French on the basis of post-focal deaccenting. For declaratives, this is realized as a low plateau extending from end of the final fall of the focused region to the end of the utterance, while for polar interrogatives (i.e., yes/no questions), this is a high plateau extending from just below the peak of the final rise in the focus region to the end of the utterance. The extent to which the left edge of a focus region is marked, however, remains an open question.

In English, the transition from pre-focal to focal region is only weakly marked. It is widely assumed, for example, that a nuclear accent near the right edge of a focal region is sufficient to mark a focus of any size. Thus, the utterances in (2) could all be marked in an identical manner (i.e., with a single nuclear accent on bats), in spite of differences in the size of the focus region (from Selkirk (1996)).
a. Mary bought a book about [bats]F.
b. Mary bought a book [about bats]F.
c. Mary bought [a book about bats]F.
d. Mary [bought a book about bats]F.
e. [Mary bought a book about bats]F.

On this basis alone, it would be impossible for a hearer to identify the location of the left edge of the focus region in such an utterance. (This is the classic focus projection problem.) In certain cases, however, it may be possible for prosodic form to mark a kind of minimum boundary for the leftward extension of the focus region. In general, it is assumed that the focal region may optionally include one or more prenuclear accents, while these are generally excluded from the prefocal region (though see Welby (2003) for experimental counterevidence to this claim). The presence of a prenuclear accent on a particular element therefore signals that that element lies inside of some focus. This effectively excludes interpretations with focus regions that do not extend at least as far leftward as the element so marked. A prenuclear accent on book in (3), for example, indicates that the left edge of the focus region is at least to the left of book, and possibly further. 
This would tend to exclude (2a) and (2b) as possible interpretations of (3), though it does not distinguish between (2c-e). It is in such a sense, then, that the left edge of focus may be said to be weakly marked in English.

In French, the pre-focal and focal regions are phrased into a series of APs, and the regularity of this phrasing is subject to conditions of rhythm and syntax. Typically, then, the pre-focal region is characterized by a more or less regular pattern of AP-final accents in a way that does not differentiate between foci of different sizes. The pattern of phrasing in (4), for example, would be consistent with the patterns of focus assignment in (5a-c).

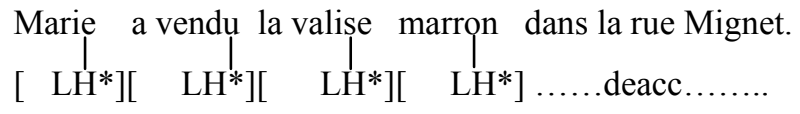
a. Marie a vendu la valise [marron]F dans la rue Mignet.
b. Marie a vendu [la valise marron]F dans la rue Mignet.
c. Marie [a vendu la valise marron]F dans la rue Mignet.

In comparison to English, then, it is the presence of tonal features, rather than their absence, which effectively conceals the left edge of the focus region in French. Recent anecdotal evidence suggests that the pre-focal region may be optionally phrased into a single unit with the focus, if the focus is very narrow (e.g., one word). If true, then the erasure of phrase boundaries and their associated accentual features pre-focally would mark a kind of maximal leftward extension of the focus region, much as the presence of pre-nuclear accents in English define a minimal leftward extension of that region. Put another way, the fact that in (4), no phrase transitions occur to the left of marron would indicate that the focus cannot extend further than the left edge of that word.

$$
\text { Marie a vendu la valise [marron]F dans la rue Mignet. }
$$

$$
\left[\mathrm{LH}^{*}\right]_{\mathrm{AP}} \ldots \ldots . \text { deacc......... }
$$

Assuming probabilistic constraints on the maximum size of a phrase, however, such outputs should generally be dispreferred except in very fast speech. In sum, the distribution of AP-phrase boundaries and their associated accents is not predicted to be a reliable marker of focus regions in French. This raises the question of whether other features besides AP-level phrasing may be associated with the left edge of focus regions.

Widespread agreement on the prosodic hierarchy of French is limited to the distinction between a single lower level unit and a single higher level unit (e.g., the AP and IP, respectively). A number of recent studies, however, have raised the possibility that an intermediate level of constituency exists for French, which may be recruited for demarcative functions at the level of syntactic or pragmatic constituency. D'Imperio \& Michelas (2009), for example, present evidence for an intermediate level of phrasing associated with the boundary between a subject and VP, whose domain is marked by systematic scaling relationships between the F0 peaks of its constituent AP-final rises. Astésano et al. (2007) present the 
results of a study showing that the distribution of the AP-initial accent is correlated with syntactic constituency for contrasts involving attachment ambiguities associated with adjectives. For the sequence les bagatelles et les balivernes saugrenues ('the crazy trifles and nonsense'), for example, the adjective saugrenues ('crazy') may be interpreted as modifying only the second NP (5a), or as modifying both the first and second NPs $(5 b)$.

\section{a. [les bagatelles] [et les balivernes saugrenues] \\ b. [les bagatelles et les balivernes] [saugrenues]}

Astésano et al. report higher rates of initial accent on the adjective when it receives a wide scope interpretation (5b), suggesting that this feature is being recruited to mark the stronger syntactic boundary occurring between the second NP and the adjective in that case. Correspondingly, more initial accents were observed at the left edge of the second NP when the scope of the adjective predicts a stronger syntactic boundary at the NP1-NP2 juncture. The authors suggest that this correlation may reflect a more general tendency for initial accents to mark an intermediate level of phrasing, which in turn is associated with alignment at the level of syntactic constituency.

If the suggestion of Astésano et al. (2007) is correct, and initial accents are a reflex of an intermediate level of phrasing, then it is reasonable to suspect that such an intermediate level may be associated with constituency domains at other levels of grammar as well. If that is true, then it should be possible to correlate initial accents with such domains. Indeed, German \& D'Imperio (2009) found preliminary evidence suggesting that initial accents are associated with the left edge of contrastive foci. In that study, initial accents appear to be more likely to occur in APs whose left edge coincides with the left edge of a focus region. The current study addresses this issue directly through a controlled production experiment involving $w h$-interrogatives with focus regions of varying sizes.

In contrast to earlier studies, the materials used in this study were not designed to evoke corrective or emphatic meaning. Thus, the feature being targeted in our study is not the accent d'insistance of Di Cristo (1996) or $H f$ of Jun \& Fougeron (2000, 2002), which may occur alone within an AP, but the initial accent $(L H i)$, whose distribution is more closely tied to cooccurrence with the AP-final rise $\left(L H^{*}\right)$. We assume instead a notion of contrastive focus in which a set of two or more closely related utterances are partitioned into information that is either shared or not shared. We further assume that such interpretations are likely to occur in contexts in which sets of utterances related in this way are uttered in sequence. Contrastive focus is typically discussed in connection with declarative utterances, though most theories of focus interpretation generalize readily to other types of utterances including interrogatives. Rooth (1992), for example, proposes a compositional view of focus, in which focus alternatives may be computed locally relative to a given constituent in a way that is independent of the semantics of the sentence-level interpretation (in other words, whether the sentence is semantically an interrogative or a declarative). For the current study, we assume that a series of question-answer pairs like those in (6) corresponds to a focus partitioning like the one indicated by F-marking.

$$
\begin{aligned}
& \text { A: Who wrote [the music]F for South Pacific? } \\
& \text { B: Rodgers. }
\end{aligned}
$$

A: Who wrote [the lyrics]F for South Pacific?

B: Hammerstein.

A: Who wrote [dialogue]F for South Pacific?

B: I don't know. 
Roughly, the interpretation of focus in these cases introduces a presupposition that the direct object portion of the background Who wrote X for South Pacific? is instantiated in the discourse by multiple contrasting (i.e., distinct) alternatives.

We now turn to the distributional properties of initial accents. The initial accent has often been characterized as optional, since APs are frequently observed without it. Known prosodic predictors of its occurrence, however, include speaking rate, number of syllables in the phrase (Welby, 2006), and morphological status (e.g., content versus function word). Astésano et al. (2007) found a simultaneous association of initial accents to both syntactic constituency and number of syllables in the phrase, which they take as evidence that the demarcative function of initial accents is first and foremost a prosodic one. Building on their model, then, our study seeks to characterize the distribution of initial accents along two dimensions: information structure and prosodic structure. In addition to testing for an association with the left edge of contrastive focus regions, we simultaneously varied the length, in number of syllables, of the lexical word units being phrased into APs. German et al. (2006) show that for English, probabilistic constraints on the accentability of certain part-of-speech categories lead to a reduced tendency for nuclear accent placement to encode focus. If it is the case that the effect of consituent length represents a similarly probabilistic constraint on the realization of initial accents, such that phrases with fewer syllables are less likely to include LHi, then constituent length and focus are predicted to interact. When a phrase is very small, for example, then initial accent may be so dispreferred that focus will have little effect on the likelihood of its occurrence. In the extreme case, initial accents on one-syllable phrases may not be well-formed. By comparison, longer phrases may actually require initial accents for rhythmic or structural reasons (e.g., constraints on maximum phrase length), and thus initial accent realization may be insensitive to focus in a different way.

In summary, our study seeks to address the following questions. First, to what extent is the left edge of focus systematically marked in French, and what role does initial accent play in this encoding? Second, what are the factors affecting the distribution of initial accents? Are they truly 'optional' as is often assumed, or can the variability in their distribution be accounted for based on constituency at other levels of description? Finally, to what extent do constraints from distinct levels of the grammar (i.e., prosody and information structure) interact? Do they make equal contributions to the likelihood that initial accent will occur, or do constraints from one level restrict the ability of initial accent to encode constituency at the other?

\section{Methods}

\subsection{Materials}

The materials consisted of 24 pairs of subject-extracted $w h$-interrogative sentences beginning with the word qui 'who'. Each target sentence included a direct object consisting of a noun phrase followed by a prepositional phrase. The noun phrase and the prepositional phrase each consisted of a single functional item followed by a noun. For the first constituent, this was one of the articles le, la, or les, while for the second constituent this was either a preposition $(\grave{a}$, en) or a prepositional contraction $(a u, a u x)$. As illustrated in (7), these target sentences occurred in one of two versions, according to the number of syllables in the second noun (short $=2$ syllables, long $=4$ syllables). Target sentences in a given pair were identical in all other respects.

a. 2 syllable: Qui a commandé le merlan aux navets ce soir?

'Who ordered the whiting with turnips this evening?'

b. 4 syllable: Qui a commandé le merlan aux macadamias ce soir?

'Who ordered the whiting with macadamias this evening?' 
Target sentences were presented as the second of a series of three information-seeking questions. Thus, as outlined in Section 1, specific patterns of focus were induced by manipulating the scope of correspondence between the target sentence and the questions occurring before and after it. In the DOfocus condition shown in (8ii), for example, the focused element is predicted to be the entire direct object 'le merlan aux navets', since the surrounding context (i.e., (8i) and (8iii)) suggests that that constituent is the relevant point of contrast. In the PP-focus condition shown in (9ii) on the other hand, the focus is limited to the prepositional phrase aux navets for similar reasons. Thus, each target item occurred in each of four conditions: DO-Focus/short, DO-Focus/long, PP-Focus/short and PP-Focus/long.

\section{(8) DO-Focus}

i. Qui a commandé l'entrecôte ce soir?

'Who ordered the rib steak this evening?'

ii. Qui a commandé [le merlan aux navets]F ce soir?

'Who ordered the whiting with turnips this evening?'

iii. Qui a commandé les gambas ce soir?

'Who ordered the shrimp this evening?'

(9) PP-Focus

i. Qui a commandé le merlan à la sauce citron ce soir?

'Who ordered the whiting with lemon sauce this evening?'

ii. Qui a commandé le merlan [aux navets]F ce soir?

'Who ordered the whiting with turnips this evening?'

iii. Qui a commandé le merlan aux câpres ce soir?

'Who ordered the whiting with capers this evening?'

The resulting 96 experimental items were divided into four lists, which were balanced for condition and block randomized. 10 filler items, consisting of a range of question types (including polar, object- and adjunct- extracted $w h$, etc.), were included in each list as distractors.

\subsection{Procedures}

Participants were seated in a sound-attenuated booth with a conversational partner, who was a native speaker of French. Participants were asked to pose each question to their partner "as naturally as possible" and then record the response on a sheet of paper. Preceding each item, a short context was read aloud by the participant. This context served both to fix the literal interpretation of the lexical items comprising the targets and to help the participants situate themselves in their assigned speaking role.

Recorded target sentences were aligned at the level of phones, syllables and words using EasyAlign (Goldman, 2007). Target sentences were labeled by the authors based on the presence and syllable affiliation of the following features:

- AP-final rise on the lexical verb $(\mathrm{V})$

- Initial rise on the first constituent (NP) of the direct object (I1)

- AP-final rise on first constituent of the direct object (F1) 
- Initial rise on the second constituent (PP) of the direct object (I2)

- AP-final rise on the second constituent of the direct object (F2)

These positions and their associated features are illustrated in (10). Note that because of the constraints on phrase-to-word alignment discussed in Section 1 and below, LH* does not occur at positions I1 and I2, while LHi similarly does not occur at positions V, F1 or F2.

$$
\begin{gathered}
\text { Qui a commandé }\left.\underbrace{\text { le merlan }}_{\mathrm{V}} \underbrace{\text { aux macadamias }}_{\mathrm{I} 1} \underbrace{\text { F1 }}_{\mathrm{I} 2}\right|_{\mathrm{F} 2} \text { ce soir? } \\
\left(\mathrm{LH}^{*}\right)(\mathrm{LHi})\left(\mathrm{LH}^{*}\right) \quad(\mathrm{LHi}) \quad\left(\mathrm{LH}^{*}\right)
\end{gathered}
$$

There is generally good agreement regarding the identification of AP-final rises $\left(\mathrm{LH}^{*}\right)$ in French. It is widely assumed, for example, that they are characterized by a prominent F0 rise that reaches a peak at or near the end of the final full (i.e., non-schwa) syllable of a content word. Typically, syllables bearing a final rise also have longer durations. Identification of $\mathrm{LH}^{*}$ was therefore based primarily on a combination of pitch track inspection and coder assessment of overall prominence. Only prominent rises in word-final positions were counted as $\mathrm{LH}^{*}$, allowing for the possibility that F0 peaks may occur just after the end of the AP-final syllable.

There is substantially less agreement regarding the identification of initial accents (LHi). Since LHi is typically not associated with syllable rhyme lengthening, overall perceived prominence is not a reliable measure. Furthermore, the pitch movements associated with initial accents may be less prominent than those associated with $\mathrm{LH}^{*}$, and may be difficult to distinguish from perturbances in the rises or falls of adjacent final accents. We therefore took a conservative approach, counting as LHi only those F0 movements which bore clear evidence of an independent high tonal event. In general, this means that candidate features included a rise from an identifiable low target, followed by a trough preceding the ascension to the peak of a following final rise (i.e., the characteristic LHiLH* pattern of Jun \& Fougeron $(2000,2002))$. Rises preceding a final rise were counted if they minimally reached a peak or plateau early in the associated syllable and showed evidence of a subsequent fall that could not be explained by microprosodic perturbances. Rises following a final rise of the previous AP were counted if the peak of the preceding final rise was reached within the AP-final syllable, and either (i) a second peak was reached or (ii) there was a stable plateau extending from the peak of preceding final rise more than $50 \%$ of the way into the following syllable. Initial rises are typically associated with the first or second syllable of the first lexical word (content word) within an AP (Welby, 2006), though it has been informally noted that they may also occur on a function word preceding the first lexical word. Early rises meeting the phonetic criteria outlined above were observed in all three positions (i.e., function word, first syllable of content word, second syllable of content word).

\subsection{Participants}

Two male and two female speakers participated in this task either voluntarily or for pay. All were first language native speakers of a continental variety of French.

\section{Results}

Speakers produced a wide range of possible patterns in the target region, though a final accent occurred at $\mathrm{V}$ in approximately $90 \%$ of all productions, and a final accent occurred at F2 in $95 \%$ of productions. 
Thus, most of the variability concerned the status of I1, F1 and I2. Overall, initial accents occurred at I1 in $21 \%$ of all productions, and $75 \%$ of these occurred on the first syllable of the noun, while $25 \%$ occurred on the function word. Late rises occurred on F1 in $84 \%$ of productions. Finally, initial accents occurred on I 2 in $39 \%$ of all productions. Of these, $38 \%$ occurred on the first syllable of the noun, $51 \%$ occurred on the second syllable of the noun, and $11 \%$ occurred on the function word.

Overall, initial accents at I1 were more frequent when this position coincided with a focus left edge (DOFoc: $32 \%$, PP-Foc: $18 \%$ ) and when the second noun was short (2-syllable: $37 \%$, 4-syllable: $15 \%$ ), though as Figure (1) shows, the effect of focus appears to be larger when the second noun is long.

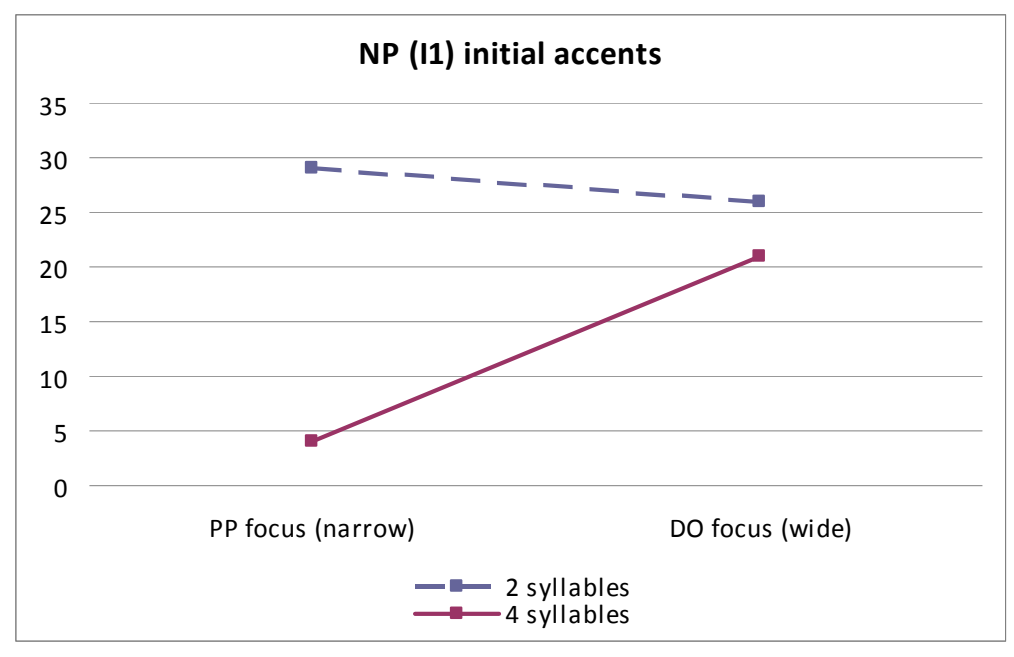

Figure 1: Likelihood of early rise on I1 by Focus and Word Length.

A mixed effects linear regression analysis (treating Focus and Length as fixed effects and participants and items as random) found the effect of length, but not focus, to be significantly correlated with the likelihood of initial accent at I1 ( $\mathrm{p}<0.05)$.

At I2, early rises were similarly more frequent when a focus edge occurred there but in contrast to I1, early rises were more frequent when the second noun was long (2-syllable: $30 \%$, 4-syllable: $83 \%$ ). As Figure (2) shows, these factors make independent contributions to the likelihood of early rise in this position. A second regression analysis found both effects to be significant at the $p<0.05$ and $p<0.1$ levels, respectively. Crucially, the analysis confirms that there is no significant interaction of Focus and Length with respect to the occurrence of initial accents at I2, suggesting that each factor makes an independent contribution to the likelihood of an initial accent. 


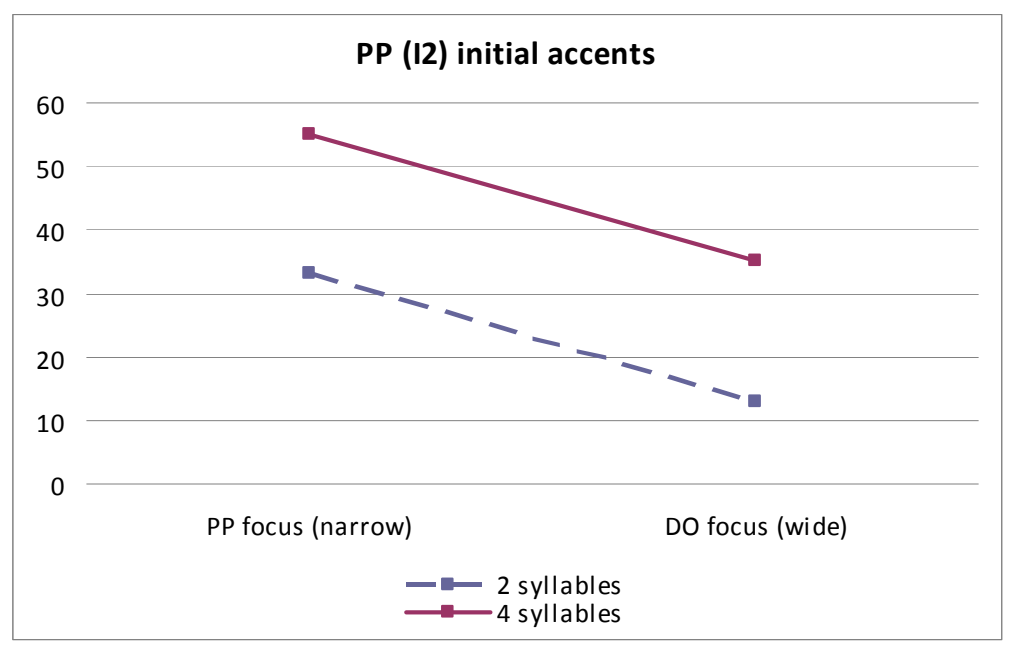

Figure 2: Likelihood of early rise on I2 by Focus and Word Length.

Finally, neither focus nor syllable number was reliably correlated with the occurrence of final accents at F2.

\section{Discussion}

The above findings establish a new link between initial accents in French and the marking of information structure. Specifically, they suggest that initial accents may serve to mark the left edge of contrastive foci. However, several facts suggest that the relationship between intial accents and focus may be indirect. After all, the correlation in our data was not very robust, and only reached significance for one position (i.e., the DO-internal position, or I2). In addition, the occurrence of initial accents was sensitive to word length as measured by syllable number. As Astésano et al. (2007) suggests, this suggests a role for initial accents that is first and foremost phonological. Even if that is the case, however, a direct demarcative link between initial accents and focus would be expected to show an interaction with phonological constraints like word length as outlined above. In other words, if the two factors both represent direct constraints on initial accent realization, then they should effectively compete for precedence - that is, the effect of length should dominate in certain regimes while the effect of focus should dominate in others. That is not what our study shows, however. Instead, the effects of both focus and word length are consistent in the sense that each is independent of the effects of the other. This strongly suggests a set of relationships that are mediated by another level of description. Putting our results together with those of Astésano et al. and D'Imperio \& Michelas, one promising hypothesis is that this mediating role is carried out by an intermediate level of phrasing.

Initial accents were not reliably linked in our study to focus edge marking at the left edge of a direct object, though the trend in the data suggests that this association may be supported by further data collection. Alternatively, this could be due to other factors. First of all, with respect to the presence of a focus edge, the experimental manipulation differed for this position (I1) as compared to the DO-internal position (I2). At I2, the experiment manipulated whether the relevant position was at a focus left edge or internal to the focus, while at I1, the experiment manipulated whether that location was at a focus left edge or external to it (i.e. in the pre-focal domain). Second, the two positions differed in terms of the syntactic boundary that was present. It remains to be tested, for example, whether the juncture between a verb and a direct object is associated with special constraints on prosodic structure that may impact the amount of variability that is permitted with regard to initial accents. 
An additional issue concerns the detection of initial accents. In this study, a conservative method was used that relied primarily on inspection of the F0 contour. As noted earlier, however, the effect of initial accents on the F0 contour may be concealed by the effects of adjacent rises. As a result, some initial accents may have gone undetected. Indeed, this is consistent with the authors' impressions: there were many cases where other acoustic properties of the syllable suggested the presence of an initial accent, but the associated position could not be labeled as such since it did not meet the established criteria. An additional correlate of initial accent is lengthening of the onset of the associated syllable. Thus, a more sensitive coding system would take into account the effect of initial accent in multiple acoustic dimensions.

By another measure, the reliability of our coding system is supported by the fact that a rather strong correlation was found between initial accents as defined by our criteria and a known phonological predictor of initial accent (constituent length). In other words, there is good evidence that the category linked in our study with focus left edges, and the category described as initial accent in other literature, are one and the same.

Our study addresses the association between initial accents and focus in production, but additional research is needed to determine whether this association is utilized in perception. Finally, while it has been suggested that the demarcative function for initial accent is mediated by an intermediate level of phrasing, this study does not address this issue directly. Additional research is needed to determine whether independent evidence for intermediate phrase constituency can be linked to the type of alignment with information structure discussed here.

\section{Références bibliographiques}

Astésano, C., Bard, E. \& Turk, A. (2007). Structural influences on initial accent placement in French. Language and Speech, 50(3), 423-446.

Clech-Darbon, A., Rebuschi, G. and Rialland, A. (1998). Are There Cleft Sentences in French? In G. Rebuschi \& L. Tuller (eds.), The Grammar of Focus, 83-118. Amsterdam: Benjamins.

Di Cristo, A. (1996). Intonation in French. In D. Hirst, \& A. Di Cristo (eds.), Intonation systems: A survey of twenty languages, 195-218. Cambridge: Cambridge.

D'Imperio, M. and Michelas, A. (2009) Mapping syntax onto prosodic structure: evidence for the intermediate phrase in French. Poster presented at Interface Discourse et Prosodie, Paris, September 9-11.

Dohen, M. and Loevenbruck, H. (2004). Pre-focal rephrasing, focal enhancement and post-focal deaccentuation in French. Proceedings of the 8th International Conference on Spoken Language Processing, 785-788.

Féry, C. (2001). Intonation of focus in French. In C. Féry \& W. Sternefeld (eds.), Audiatur Vox Sapientes: A Festschrift for Arnim von Stechow, 153-181. Berlin: Akademie Verlag.

German, J., Pierrehumbert, J. and Kaufmann, S. (2006). Evidence for phonological constraints on nuclear accent placement. Language, 82(1), 151-168.

German, J., and D'Imperio, M. (2009). Information structure and the alignment of phrasal features in French quinterrogatives". Poster presented at Interfaces Discours et Prosodie, Paris.

Goldman, J.-P. (2007). EasyAlign v26.08.07. Downloaded 4/16/2009: <http://latlcui.unige.ch/phonetique/>.

Jun, S.-A., and Fougeron, C. (2000). A phonological model of French intonation. In A. Botinis (ed.), Intonation: Analysis, modeling and technology. Dordrecht: Kluwer.

Jun, S.-A., and Fougeron, C. (2002). Realizations of accentual phrase in French. Probus, 14, 147-172.

Rooth, M. (1992). A theory of focus interpretation. Natural Language Semantics, 1, 75-116.

Selkirk, E. (1996). Sentence prosody: Intonation, stress, and phrasing. In J. Goldsmith (ed.), The Handbook of Phonological Theory 550-569. London: Basil Blackwell.

Touati, P. (1987). Structures Prosodiques du Suédois et du Français. Lund: University Press. 
978-2-7598-0534-1, Paris, 2010, Institut de Linguistique Française

Phonétique, phonologie et interfaces

DOI $10.1051 / \mathrm{cmlf} / 2010225$

Welby, P. (2003). Effects of pitch accent position, type, and status on focus projection. Language and Speech, 46(1), 53-81.

Welby, P. (2006). French intonational structure: Evidence from tonal alignment. Journal of Phonetics, 34, 343-371. 